

\section{REVISTA \\ TEORÍA Y PRÁCTICA \\ DE LA \\ ARQUEOLOGÍA HISTÓRICA LATINOAMERICANA}

ISSN: 2250-866X (impreso) | ISSN: 2591-2801 (en línea)

AÑo VIII, VOLUMEN 8, PRIMAVERA DE 2019

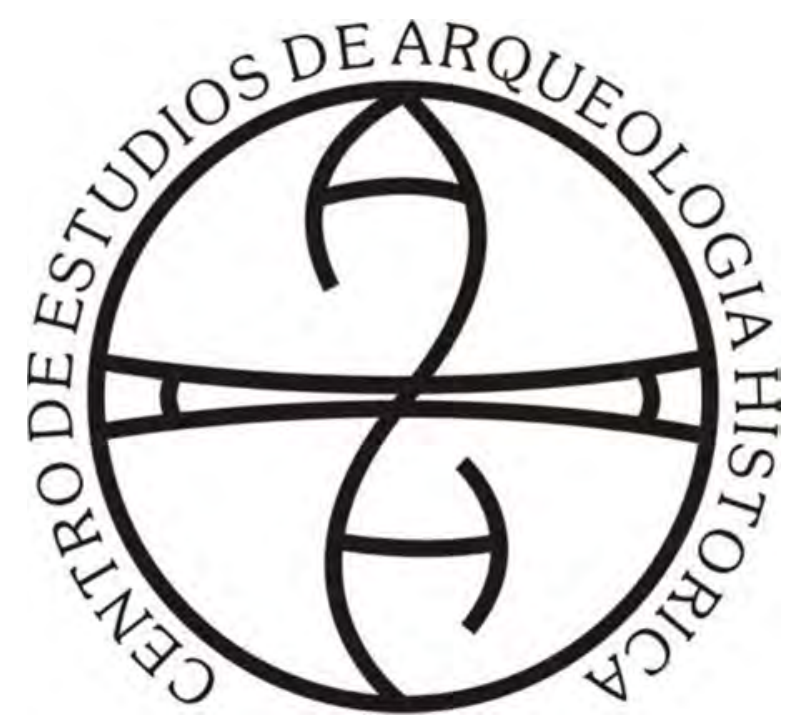

Centro de Estudios de Arqueología Histórica

FACULTAD DE HUMANIDADES Y ARTES | UNIVERSIDAD NACIONAL DE ROSARIO 
(Universidad Nacional de Rosario, Universidad Nacional de Río Cuarto,

Universidad Nacional de San Juan, Universidad de la República, Universidad Nacional de Trujillo)

\author{
AUTORIDADES DE LA UNIVERSIDAD NACIONAL DE ROSARIO \\ RECTOR: Lic. Franco Bartolacci \\ VICE-RECTOR: Od. Darío Macía \\ SECRETARIO GENERAL: Prof. José Goity \\ SECRETARIA ACADÉMICO Y DE APRENDIZAJE: Dr. Marcelo Vedrovnik \\ SECRETARÍA DE CIENCIA TECNOLOGÍA E INNOVACIÓN \\ PARA EL DESARROLLO: Ing. Guillermo Montero.
}

\author{
AUTORIDADES DE LA FACULTAD DE HUMANIDADES Y ARTES \\ DECANO: Prof. Alejandro Vila \\ VICEDECANA: Prof. Marta Varela \\ SECRETARIA ACADÉMICA: Dra. Marcela Coria
}

\author{
AUTORIDADES DEL CENTRO DE ARQUEOLOGÍA HISTÓRICA \\ DIRECTORA: Dra. Ana Rocchietti \\ SECRETARIA: Prof. Nélida de Grandis \\ PROSECRETARIA: Lic. Marianela Bizcaldi
}

DIRECTORAS - EDITORAS:

Dra. Ana Rocchietti y Prof. Nélida De Grandis

SECRETARIA DE EDICIÓN: Dra. Irene Dosztal

Este número es co-edición de las ponencias

del VIII Congreso Nacional de Arqueología Histórica (2018) entre:

Centro de Estudios en Arqueología Histórica: Directora Ana Rocchietti

Centro de Estudios en Arqueología Regional: Director Fernando Oliva

Centro de Estudios en Arqueología Subacuática: Directora Mónica Valentini

Departamento de Arqueología, Escuela de Antropología: Director Fernando Oliva
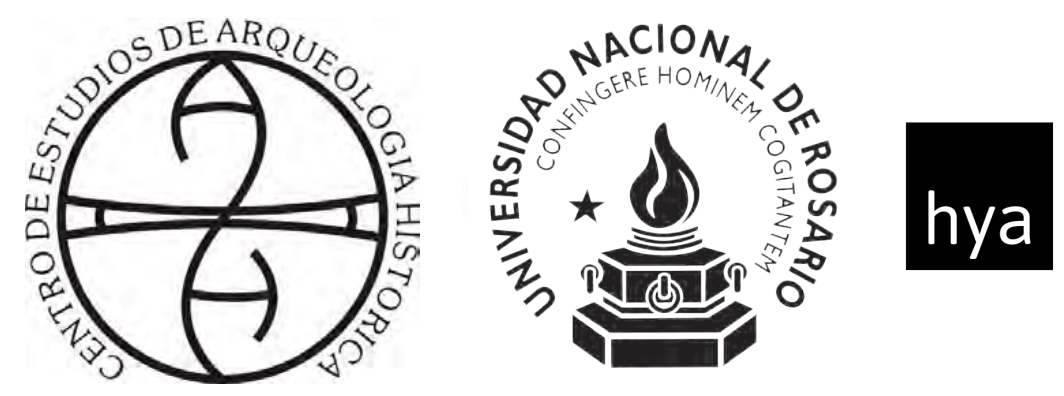

Facultad de Humanidades

y Artes_UNR
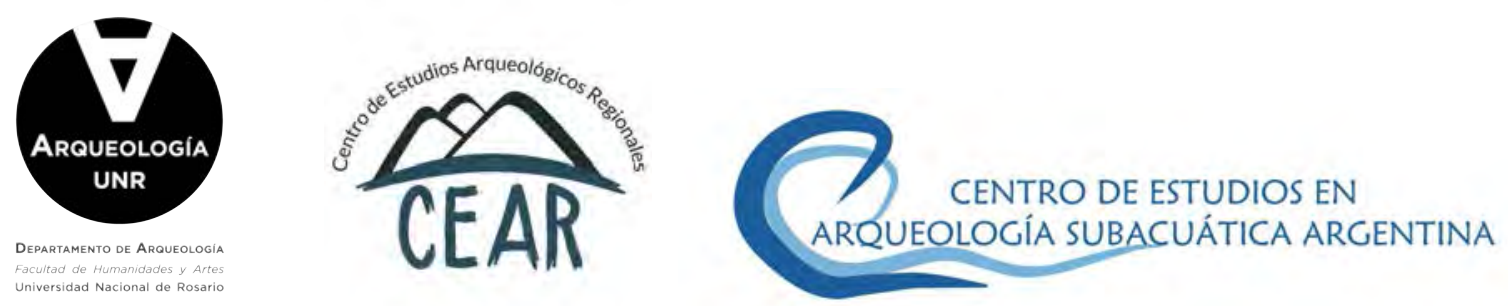
Comité Permanente de los Congresos Nacionales de Arqueología Histórica

Dr. Daniel Schávelzon (Universidad Nacional de

Buenos Aires)

Prof. María Teresa Carrara (Universidad Nacional de Rosario)

Prof. Carlos Baldassarre (Museo Municipal de Río

Grande, Tierra del Fuego) in memoriam

Dr. Mariano Ramos (Universidad Nacional de Luján, CONICET)

Dr. Horacio Chiavazza (Universidad Nacional de Cuyo)

Dra. Ana María Rocchietti (Universidad Nacional de

Rosario, Universidad Nacional de Río Cuarto)

Lic. Facundo Gómez Romero (Universidad Autónoma

de Barcelona)

\section{Comité Científico}

Dra. Tânia Andrade Lima (Universidade Federal do Rio de Janeiro)

Prof. Réginald Auger (CELAT/Département des

Sciences Historiques, Université Laval, Canadá)

Dr. Roberto Bárcena (Universidad Nacional de Cuyo, CONICET)

Dra. Marta Bonaudo (Universidad Nacional de Rosario, CONICET)

Dr. Leonel Cabrera (Universidad de la República, Uruguay)

Dr. Luis María Calvo (Universidad Católica de Santa

$\mathrm{Fe})$

Prof. Juan Castañeda Murga (Universidad Nacional de

Trujillo, Perú)

Dr. Carlos Ceruti (Museo de Ciencias Naturales y

Antropología "Prof. Antonio Serrano". Paraná)

Dr. Horacio Chiavazza (Universidad Nacional de Cuyo)

Dra. Silvia Cornero (Universidad Nacional de Rosario)

Prof. Pedro Paulo Funari (Universidade Estadual de

Campinas, Brasil)

Lic. Jorge A. Gamboa Velásquez (Universidad Nacional

Santiago Antuñez de Mayolo, Perú)

Dr. Eduardo Alejandro García (Universidad Nacional de

San Juan, CONICET)

Prof. Nélida De Grandis (Universidad Nacional de

Rosario)

Dr. Juan Bautista Leoni (Universidad Nacional de

Rosario, CONICET)

Dra. Amancay Martínez (Universidad Nacional de San

Luis)

Dra. Catalina Teresa Michieli (Universidad Nacional de

San Juan, CONICET)

Lic. Fernando Oliva (Universidad Nacional de Rosario)

Ing. Adrián Pifferetti (Universidad Tecnológica
Nacional Regional Rosario)

Dr. Mariano Ramos (Universidad Nacional de Luján, CONICET)

Dra. Ana María Rocchietti (Universidad Nacional de Rosario)

Dr. Daniel Schávelzon, (Universidad Nacional de Buenos

Aires, CONICET)

Dra. Carlota Sempé (Universidad Nacional de La Plata)

Dr. Mario Silveira (Universidad Nacional de Buenos Aires)

Dra. Silvia Simonassi (Universidad Nacional de Rosario)

Dra. Alicia Tapia (Universidad Nacional de Buenos Aires, Universidad Nacional de Luján)

Lic. Mónica P. Valentini (Universidad Nacional de Rosario)

Agrim. Benito Vicioso (Universidad Nacional de Rosario)

\section{Evaluaron este volumen}

Roberto Bárcena, María Teresa Boschin, Leonel Cabrera, Ulises Camino, María Rosa Carbonari, Carlos Ceruti, Horacio Chiavazza, Nicolás Ciarlo, Silvia Cornero, Eduardo Crivelli, Javier García Cano, Martín Gentinetta, María Laura Gili, Carlos Landa, Matilde Lanza, Melina Malandrino, Sebastián Pastor, Victoria Pedrotta, Josefina Piana,

Mercedes Podestá, Mariano Ramos, Daniel Schavelzon, Diana Tamburini, Mónica Therrien, Mónica Valentini y María Teresa Boschin

\section{Diseño y diagramación}

Eugenia Reboiro

(eugenia.reboiro@gmail.com)

\section{Curadoría}

Ana Rocchietti e Irene Dosztal

Foto de tapa: imagen del texto de Croce.

\section{Propietario responsable:}

Facultad de Humanidades y Artes, Universidad Nacional de Rosario Centro de Estudios de Arqueología Histórica

Entre Ríos 758. Rosario, provincia de Santa

Fe (2000). Argentina.

Telf.: +54 (0341) 4802670

E-mail: ceahunr@gmail.com

Decreto Ley 6422/57 de Publicaciones

Periódicas 


\section{Índice}

Editorial.

Arqueología histórica: programa de investigación y dimensiones epistemológicas...9 Ana María Rocchietti

De lozas, iglesias y machaqueños. Primeros pasos hacia una arqueología histórica en la cuenca norte del río desaguadero (La Paz, Bolivia).

Salvador Arano Romero

Identificación arqueológica de acciones militares en el campo de batalla de Cepeda, 1859.

Juan B. Leoni, Lucas H. Martínez, Cecilia Arias Morales, Daniela Cadenas,

Faustino Godoy, Mauro Ganem, María de la Paz Blanche y Héctor Meletta

Para una historia de la arqueología urbana en Buenos Aires (1848-1910) .59

Daniel Schávelzon y Francisco Girelli

Definiendo la cultura material colonial a partir de colecciones arqueológicas del Museo de La Plata.

Melina Bednarz, Julieta Penesis y Ana Igareta

La tangibilidad del conflicto: Arqueología del presente en las fronteras del norte santafesino....

Paula Del Río y Silvia Cornero

Arqueología histórica: evidencia material en el paisaje del establecimiento jesuita "La saladilla” (quebrada de Saladillo, La Rioja, Argentina). Juan Carlos Giuliano, Maira Ayelén Carrizo y María Soledad Gheggi

Graffiti ¿evidencia arqueológica o acto vandálico?. Camila Oliva

Arqueología histórica de los sistemas hidráulicos de la Hacienda

Jalpa de Cánovas, Guanajuato, México, y su relación con el sistema-mundo, Siglos XVIII-XIX

José Alberto Aguirre Anaya y Edgar Quispe Pastrana 
Paseo del bajo: una trinchera en la historia de Buenos Aires.................................143 Federico Martín Croce

Diferentes concepciones del patrimonio y su aplicación a la Casa Histórica de Tucumán también llamada Casa de la Independencia........................................155 Guillermo Etchevers

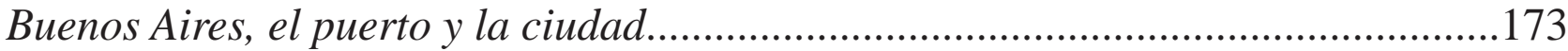
Mónica P. Valentini y Javier García Cano 


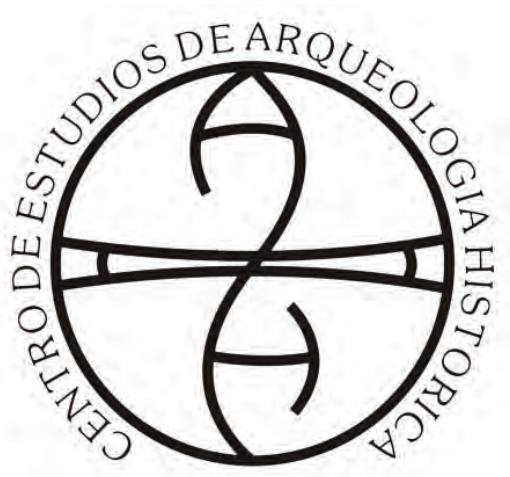

Centro de Estudios de Arqueología Histórica

Universidad Nacional de Rosario
Teoría y Práctica de la Arqueología Histórica

Latinoamericana | Año VIII. Vol. 8 | 2019

Revista del Centro de Estudios de Arqueología

Histórica, Facultad de Humanidades y Artes, Universidad Nacional de Rosario

https://teoriaypracticaah.unr.edu.ar/index.php/index ceahunr@gmail.com

ISSN en línea: 2591-2801

ISSN versión impresa: 2250-866X

\title{
Paseo del bajo:
}

\section{UNA TRINCHERA EN LA HISTORIA DE BUENOS AIRES}

\author{
Federico Martín Croce*
}

\section{Resumen}

Desde los orígenes de lo que hoy conocemos como la Ciudad Autónoma de Buenos Aires, las actividades en relación al puerto fueron la base de sustento, de desarrollo y una de las principales formas de dominio económico de la ciudad sobre el resto del territorio del Virreinato primero y de la República después. La relación de la primitiva aldea con el río, su pobre o nula infraestructura portuaria y la muy moderna ciudad actual, con sus grandes puertos y su casi intacta hegemonía en términos de actividades comerciales asociadas a la exportación e importación de todo tipo de productos, hicieron que la fisonomía urbana y la relación de los habitantes de la ciudad con el río se vieran modificadas notablemente. Este proceso histórico es posible verlo a partir de los diferentes estratos sedimentarios que se fueron acumulando a través de los años y que recientemente han quedado expuestos por una mega obra.

La construcción del Paseo del Bajo ha sido, tal vez, una de las oportunidades más interesantes para rescatar parte de ese pasado, ya que se trata de una operación urbana que requirió de una excavación de unos $3 \mathrm{~km}$ de longitud y $18 \mathrm{~m}$ de profundidad. Lamentablemente no hubo una intervención de profesionales idóneos en materia de rescate arqueológico,, por lo que se perdió la posibilidad de estudiar una parte de la historia Argentina en condiciones muy poco convencionales pero muy provechosas en cuanto a la cantidad de material removido.

Palabras clave: Infraestructura, Obra pública, Ciudad, Historia urbana

Abstract

From the origins of what we know today as the City of Buenos Aires, the activities in relation with the harbor were the base of the economic sustenance, development and one of the main forms of economic domination of the city over the rest of the territory, first in the Viceroyalty and later in the Republic. The relation of the primitive village with the river, its poor or nonexistent port infrastructure and in the cu-

* Cátedra de Historia de la Arquitectura (Pernaut-García Cano) / Archivo de Imágenes Digitales. Facultad de Arquitectura, Diseño y Urbanismo de la Universidad Nacional de Buenos Aires. 
rrent modern city, with its large harbor and its almost intact hegemony in terms of commercial activities associated with the export and import of all types of products, the aspect of the city and the relation of the inhabitants with the river were modified remarkably. This historical process is possible to see it from the different sedimentary strata that have accumulated over the years and that have recently been exposed by a mega construction.

The construction of Paseo del Bajo has been, perhaps, one of the most interesting opportunities to rescue part of that past, since it is an urban operation that required an excavation of about $3 \mathrm{~km}$ long and $18 \mathrm{~m}$ deep. Unfortunately there was no intervention by qualified professionals in the field, so the possibility of studying a part of Argentine history was lost in very unconventional but profitable conditions, in terms of the amount of removed material.

Keywords: Infrastructure, Public works, City, Urban history

\section{Palabras preliminares}

Este estudio tiene como objetivo acercar una mirada sobre el problema del tratamiento del patrimonio en la Argentina, apelando a lo que tal vez sea una de las obras más grandes de la ciudad de Buenos Aires en los últimos 60 años. Las brutales intervenciones en la zona en cuestión no son algo nuevo, como veremos más adelante. Pero en la actualidad se ha perdido la oportunidad de revisar y rescatar parte de nuestra historia por negligencia de las clases dirigentes pero también por la pasividad de quienes nos dedicamos a la reconstrucción de la historia, independientemente del campo profesional de pertenencia.

El carácter ensayístico de este trabajo no implica un agotamiento del caso abordado, todo lo contrario, es apenas el inicio de una búsqueda más profunda que se inició a partir del propio trabajo profesional en la obra y que desembocó en la necesidad de comprender que uno se encontraba trabajando no solo sobre un pedazo de tierra, si no que estaba operando sobre un sitio arqueológico. La selección de los hechos históricos de los que se vale el trabajo tiene como finalidad establecer una correlación entre obras de infraestructura y es posible que se hayan dejado de lado hitos de la historia Argentina que podrían estar. Tal vez las conclusiones exceden el marco planteado, deben ser tomadas como una opinión del autor y tendrán un carácter provisorio mientras la continuación de la investigación no arroje nuevos resultados.

\section{Los orígenes de la ciudad puerto}

Las primeras ocupaciones españolas del área de la ciudad que se tomó para el estudio se remontan a la primera y segunda fundación de Buenos Aires encabezadas respectivamente por Pedro De Mendoza en 1536 y por Juan De Garay en 1580 (Imagen 1), siendo la segunda la más exitosa. El fallido asentamiento de Pedro De Mendoza se ubica al sur, cerca de la boca del Riachuelo, aprovechando las ventajas naturales de los accidentes geográficos que eran propicios para la utilización como fondeadero. El 11 de junio de 1580 Juan de Garay instala una nueva aldea un poco más al norte, dando origen a la Ciudad de la Santísima Trinidad y al puerto de Santa María de los Buenos Aires. Originalmente se pensó que la función principal de la ciudad se enmarcaba en la necesidad del Imperio Español de sacar la plata del Potosí de manera más segura y rápida, agregando una ruta por el océano Atlántico que permitiera un control más efectivo del comercio en las colonias. "A partir de ese momento, y bajo el impulso de Ortiz de Zárate se acelera el proceso que culminará con la fundación de Buenos Aires, que resultará la tan ansiada 'Puerta de la Tierra’” (Astigarraga, 2000, p.329). 
Por supuesto la realidad fue muy distinta, ya que en un principio la ciudad se encontraba bastante aislada del resto del virreinato, por lo que sus pobladores se volcaron al contrabando de mercancías para poder subsistir, comerciando fundamentalmente con los portugueses y los ingleses. (Imagen 2)

Para finales del siglo XVIII los ingleses y los portugueses veían en Buenos Aires una clara oportunidad para sus negocios y una pieza clave de la geopolítica en esos tiempos. Finalmente en 1776 se conforma el Virreinato del Río de la Plata y se declara a Buenos Aires capital del mismo, elevando su estatus administrativo y comercial. A partir de estos años el crecimiento de la ciudad se vuelve sostenido, su expansión se da primero hacía el sur y luego hacia el norte y el oeste, contando siempre como límite natural el Río de la Plata al este y el Riachuelo hacía el sur.

Con el paso del tiempo esta relación de la ciudad con el río ha sufrido una serie de cambios asociados a ciertas variables que tienen que ver con el desarrollo de los modos de transporte de mercancías, las condiciones hidrológicas del Río de la Plata y las diferentes obras de infraestructura portuaria sobre la costa. Cuando los primeros pobladores se empezaron a instalar en el territorio, las complicaciones para poder acceder a tierra firme desde el agua, y viceversa, eran muchas ya que es escasa producto de la gran cantidad de bancos de arena que se generan con los sedimentos que arrastran los afluentes que alimentan la cuenca. Esta condición natural impedía el acceso de buques de gran calado, por lo que la transferencia de mercancías o de personas desde las grandes naves se hacía a través de embarcaciones más pequeñas que se acercaban hasta los bañados del río y de ahí en carreta hasta tierra firme. Un interesante relato de un portugués anónimo grafica, incluso, las debilidades defensivas de la ciudad en el siglo XVII:

"La ciudad no tiene ninguna fuerza. Está puesta y edificada a la orilla del mismo río, y los navíos que a ella vienen se quedan sin llegar a la orilla, a un tiro de mosquete, y pueden echar ancla, que el río corre muy manso y apacible. Las casas del gobernador casi que bate el agua en ellas. Esta casa tiene un pequeño torreón que está frontero con el río y en él están cuatro pequeños cañones de batir, y no hay parte donde tenga otra ninguna defensa. Para querer entrar a la ciudad, por cualquiera parte del río pueden echar gente en tierra en barcos o lanchas, porque el río corre muy manso por todas partes y no tiene bosque ni monte, toda es tierra llana”. (Trujillo, 2017, p. 8)

\section{La infraestructura portuaria}

El devenir histórico de la ciudad y los avances técnicos de fines del siglo XVIII hacían cada vez más complejo el proceso de ingreso o egreso de mercaderías o personas al territorio nacional. Durante el siglo XIX las luchas independentistas y el proceso de unificación del territorio hicieron que las primeras obras serias de infraestructura comenzaron a materializarse en 1855, finalizando en 1857 con la inauguración del muelle de pasajeros en el entonces denominado Bajo la Merced (hoy Av. Leandro N. Alem) y la Aduana de Buenos Aires (Aduana Taylor). La ubicación de dicho muelle se encontraba comprendida entre las actuales calles Bartolomé Mitre y Pte. Perón y el edificio de la Aduana debajo de la actual Casa de Gobierno y del paseo de la Rábida (Imagen 3).

El cese de las luchas intestinas que finalizaron con la unificación del territorio nacional, la formación de un estado moderno con todas las implicancias legales y el establecimiento de una cierta estabilidad política hicieron florecer la economía y permitieron financiar esta primera experiencia más o menos grande en materia portuaria.

"Inspirada en el notorio empuje que cobraba el puerto de Buenos Aires y símbolo del poderío económico porteño, la aduana comenzó a construirse en 1855 y se la inauguró en 1857 con un 
Teoría y Práctica de la Arqueología Histórica Latinoamericana | Año VIII. Vol. 8 | 2019

ISSN en línea: 2591-2801 | ISSN versión impresa: 2250-866X

costo de \$ 16.000.000, una fortuna en su tiempo. Estaba situada con frente al río, justo detrás de la Casa de Gobierno, antiguamente Fuerte y Palacio de los Gobernadores que aún existía en esa época, por si su simbolismo fuera poco. Pese a eso y a los múltiples anexos y obras secundarias que se le hicieron, en 1894 fue demolida para dar lugar a las obras de Puerto Madero ya con una concepción más amplia del conjunto portuario.” (Schávelzon, 2010, p. 71)

Para finales del siglo XIX, con el comienzo de la consolidación del modelo agroexportador, la aparición de buques con dimensiones cada vez más importantes y la necesidad imperante de sacar la producción agropecuaria del país, vuelven a poner en jaque a la infraestructura portuaria, dejándola obsoleta a los fines comerciales para los que fue diseñada.

Frente a este nuevo desafío, dos personajes de gran relevancia histórica, se proponen dar nuevas soluciones para los requerimientos en materia de infraestructura. El comerciante e historiador Eduardo Madero y el Ing. Luis A. Huergo plantearon dos esquemas portuarios muy diferentes y que reflejaban dos miradas muy distintas sobre cómo abordar el problema. El primero establecía una secuencia de diques con dársenas de acceso y egreso, frente a la ciudad. El segundo estableció un sistema de dársenas con espigones que permitiría un crecimiento hacía el norte, si las necesidades derivadas de las actividades comerciales así lo requerían.

Finalmente el proyecto ganador, en una situación un poco irregular, es el del comerciante Eduardo Madero (Imagen 4). Las obras para la ejecución de este proyecto arrancaron en 1884, comenzando con el relleno del río frente a lo que hoy es el Bajo Porteño (el eje Av. Paseo Colón y la Av. Leandro N. Alem). El diseño original consistía en una serie de diques interconectados mediante esclusas, paralelo a la costa, con una gran dársena de acceso (Dársena Norte) y una dársena al sur que conectaba con la desembocadura del Riachuelo. Del otro lado de los diques se emplazarían una serie de barracas y de silos/elevadores de granos que durante poco más de un cuarto de siglo fueron los encargados de recibir y estibar la producción agropecuaria de la pampa húmeda en los buques de carga. La notable modificación del perfil urbano fue tan fuerte que cambió para siempre la manera de concebir el río para los porteños. Este monumental relleno que elimina las visuales del Río de la Plata, desde el barrio de La Boca hasta Retiro se convirtió, poco a poco, en una barrera que eliminó del imaginario popular la condición de la ciudad puerto.

Existieron muchos desaciertos a la hora de diseñar esta sucesión de diques, haciendo que a los pocos años de inaugurado quedara obsoleto fundamentalmente por el dimensionado de las esclusas, que no permitían el paso de los nuevos buques transatlánticos, que hacía un tiempo se venían construyendo en acero logrando ampliar considerablemente la manga de las naves. Tal fue el infortunio con este puerto que se estima que el uso de la capacidad total instalada no se pudo sostener por más de 14 años y antes de cumplir un cuarto de siglo se realizan inversiones para dar lugar a un puerto más grande y moderno:

"Buenos Aires era considerado en 1887 el décimo segundo puerto del mundo; el tonelaje de los barcos que entraban y salían de Puerto Madero era de 4.000.000 de toneladas,- cuando se inicia el siglo llega a 10.000.000 y cuando se decide la ampliación era de 20.000.000 de toneladas y 3.000 buques. Una ley del 1 de septiembre de 1907 decide una inversión de 25 millones de pesos oro en la ampliación del Puerto Madero, obra que sería resuelta mediante un concurso. El ingeniero Corthell proponía el crecimiento del nuevo puerto delante del existente y el ingeniero Huergo sostenía la readaptación del viejo puerto unificando las dársenas. El Ministerio de Obras Públicas, en enero de 1909, dispuso que la ampliación se realizara hacia el norte de Puerto Madero y resultó ganadora del concurso la empresa Thomas Walker y Cía., quienes habían sido constructores del anterior puerto. En septiembre de 1911 se celebra el contrato con esa empresa y se comienzan las 
Teoría y Práctica de la Arqueología Histórica Latinoamericana | Año VIII. Vol. 8 | 2019

ISSN en línea: 2591-2801 | ISSN versión impresa: 2250-866X

obras, que fueron concluidas en su totalidad en 1928. Entre 1911 y 1919 se construyeron las obras básicas de las cinco dársenas en forma dentiforme ya anticipada por Huergo en 1882, completándose así el crecimiento de sur a norte en la secuencia de Riachuelo, Dock Sur, Puerto Madero y Puerto Nuevo.” (Anónimo, HISTARMAR)

Para 1909 se vuelve insostenible la operación de las instalaciones, por lo que finalmente, tras varias idas y vueltas sobre qué hacer con las no tan viejas instalaciones portuarias (en general estas obras se diseñan para durar bastante más que 20 años), el gobierno nacional autoriza la construcción del puerto diseñado por el Ing. Luis A. Huergo (Imagen 5). Considerando la imposibilidad de ampliar el puerto existente, el Ing, Huergo se vuelca a la idea original que había postulado frente a la propuesta de E. Madero. La construcción se valía de una serie de espigones que de manera intercalada irían formando 5 dársenas de ultramar, con posibilidad de ampliar las instalaciones hacía el norte si esto era requerido. Las obras de lo que hoy llamamos Puerto Nuevo empiezan a funcionar a finales de la década del 20' quedando la zona de Puerto Madero abandonada.

Durante la mayor parte del siglo XX esta serie de edificios industriales en desuso se encontraban vedados al público por tratarse de una zona portuaria restringida. Existieron varios proyectos inmobiliarios y a partir de la década del 70' se comienza a rellenar la zona donde se encuentran los viejos balnearios. Ya en la década del 80', este relleno se convierte en un lugar donde el río deposita todo tipo de sedimentos, trayendo consigo fauna y flora que fue moldeando un ecosistema nuevo pero característico del contexto geográfico ribereño. En el año 1986 se declara este territorio de 350 hectáreas como reserva ecológica.

En sintonía con el mundo neoliberal en la década de los 90’, las antiguas instalaciones portuarias son sometidas a concurso de ideas, generándose diferentes alternativas para recuperar una importante superficie de tierra a metros de la Casa Rosada. El plan maestro llevado a cabo por los arquitectos Juan Manuel Borthagaray, Cristian Carnicer, Pablo Doval, Enrique García Espil, Mariana Leidemann, Carlos Marré, Rómulo Pérez, Antonio Tufaro y Eugenio Xaus, junto con el asesoramiento del ayuntamiento de Madrid, se convierte en un lujoso barrio porteño, aumentando radicalmente la circulación de tránsito de vehículos y de personas en una zona abandonada durante décadas. Se logra una resignificación de un área de la ciudad que se vio degradada durante, por lo menos, 70 años. La conformación del barrio más joven de la ciudad significó el agregado de una nueva capa de historia en un territorio que ya contaba, como se menciona más arriba, con una muy larga lista de intervenciones que quedaron ocultas bajo el suelo.

\section{La trinchera del Paseo del Bajo}

La idea de realizar una autopista que terminara de cerrar el circuito entre el norte y el sur de la ciudad estableciendo una mejor conexión con el conurbano bonaerense no es una idea nueva. Por lo menos desde finales del siglo XIX y más fuertemente a mediados del siglo XX, existieron múltiples proyectos para una vinculación entre el norte y el sur. Desde propuestas decimonónicas con grandes avenidas y bulevares, hasta conceptos más modernos como el que propone el plan regulador de la década del 50' (Imagen 6):

“El Plan Regulador aprobado en 1958 desarrolló el trazado de la autoruta de la Costa como una de sus prioridades. En la búsqueda de un equilibrio estructural fue un instrumento de descentralización y distribución de funciones frente al borde urbano (Ciudad universitaria, Aeropuerto, Puerto, Conjunto de Catalinas Norte y Sur, Casa Amarilla, terrenos del antiguo puerto y conexión 
Teoría y Práctica de la Arqueología Histórica Latinoamericana | Año VIII. Vol. 8 | 2019

ISSN en línea: 2591-2801 | ISSN versión impresa: 2250-866X

entre las riberas del norte y del sur). Dentro de ese panorama se reiteró la necesidad de desactivar el Puerto Madero, ya esbozada en el Proyecto Orgánico de 1925. Del mismo modo, desde una óptica metropolitana, los “jardines de la costa norte” y aquellos que liberarían las instalaciones portuarias en continuidad con la Costanera sur, eran sede de las amplias áreas recreativas extendidas sobre el conurbano: hasta el Tigre y desde Avellaneda hacia La Plata, a los efectos de resolver las “carencias" de espacios verdes y deportivos. En contrapunto, los equipamientos del sur y la vivienda social asumían una importancia creciente.” (Novick, 2001, p.18)

En la primera década del siglo XXI, el desarrollo inmobiliario del barrio de Puerto Madero y las necesidades de transporte de mercancías en el eje Norte - Sur se volvieron incompatibles debido a los ingentes volúmenes de vehículos que se movilizan en la traza de Av. Huergo-Av. Madero. Sumada a esta complejidad y tal como previó el Ing. Luis A. Huergo, el puerto de Buenos Aires tiene prevista una importante ampliación hacia el norte de su actual localización, con el objetivo de renovar sus instalaciones y así duplicar las operaciones que se dan en la actualidad.

Para dar solución a este nuevo desafío se propuso una intervención urbana en la que se excava una trinchera de aproximadamente $3 \mathrm{~km}$ de longitud, 30 metros de ancho y 18 metros de profundidad (Imagen 7). Con esta obra se espera poder afrontar la demanda cada vez más importante de movimientos de camiones producto de las operaciones portuarias y un descongestionamiento en el eje Norte - Sur (al menos en superficie).

Nuevamente nos encontramos con una operación sobre un terreno que parecía que ya no iba a ser tocado, resignificando otra vez un espacio urbano por el que transcurrió gran parte de la historia de la Ciudad de Buenos Aires y de la Argentina.

A la hora de elegir un proceso constructivo, los ingenieros optaron por realizar muros colados. Esto significa realizar una excavación de mucha profundidad y poco espesor, en la cual se instalaban las armaduras y luego se realizaba el colado de hormigón, formando un muro de contención en ambas márgenes de la obra, que podía variar dependiendo de las necesidades constructivas. Luego de terminados los muros y sus correspondientes puntales se procedía a la excavación de la trinchera dejando expuestos, temporalmente, los suelos compuestos por rellenos generados por la mano del hombre en diferentes etapas de la historia de Buenos Aires. Incluso llegándose a encontrar los estratos conformados por la sedimentación natural del Río de la Plata en épocas en las que sus aguas bañaban las antiguas costas de la ciudad. También se han identificado napas a la altura de la Av. Independencia (a -18m.) que podrían tratarse una suerte de continuidad subterránea del antiguo cauce del zanjón de Granados, aunque lamentablemente no se pudo verificar con datos fehacientes.

La composición de la mayor parte del suelo que se encontró durante la excavación, según los estudios geotécnicos, se compone de restos que van desde basura hasta escombros y diferentes tipos de áridos que vienen de diversas localizaciones de la ciudad. Uno de los principales problemas para los ingenieros estructurales que desarrollaron los proyectos ejecutivos de obra fue la imprevisibilidad respecto de la composición de los estratos, lo que originó enormes desafíos técnicos para poder trabajar con los diferentes materiales con los que se fueron encontrando durante la excavación. Un ejemplo de la dificultad es lo que durante la obra se denominó “Nudo Retiro” (Imagen 8). Esta zona comprendida por la Av. Antártida Argentina entre Av. Córdoba y Av. De Los Inmigrantes tuvo constantes desmoronamientos de suelo, producto de la cercanía de las napas (de hecho es terreno ganado al río) y de una importante discontinuidad de los tipos de material que conformaban el suelo.

Lamentablemente, no hubo registros exhaustivos que permitieran dar precisiones sobre los oríge- 
nes de los estratos de suelo. Aunque existieron estudios geotécnicos que permiten calcular la capacidad portante o medir algunas variables químicas de los mismos, no se los puede tomar como definitivos para un estudio profundo sobre, por ejemplo, la procedencia de los rellenos que dieron lugar al antiguo puerto de Buenos Aires.

Tampoco se trabajó con profesionales idóneos en materia patrimonial, que pudieran dar provecho a una excavación de esta magnitud en una zona de gran valor arqueológico. Difícilmente se tenga oportunidad de estudiar los suelos que se removieron de la zona, ya que fueron utilizados como material de relleno para el nuevo espigón del Puerto Nuevo y para el relleno del corrimiento de la traza de la Av. Costanera Rafael Obligado, frente al aeroparque.

Independientemente de las claras objeciones que se pueden hacer en cuanto a la forma de operar sobre una porción de territorio con gran valor patrimonial para la Ciudad de Buenos Aires en particular y para la Argentina en general, la materialización del Paseo del Bajo es una etapa más en la historia de la ciudad. Es una marca que se suma al palimpsesto de obras y de hechos históricos que dieron fundación a la ciudad de Buenos Aires o que la hicieron crecer como la metrópolis pujante que hoy es.-

\section{Imágenes}

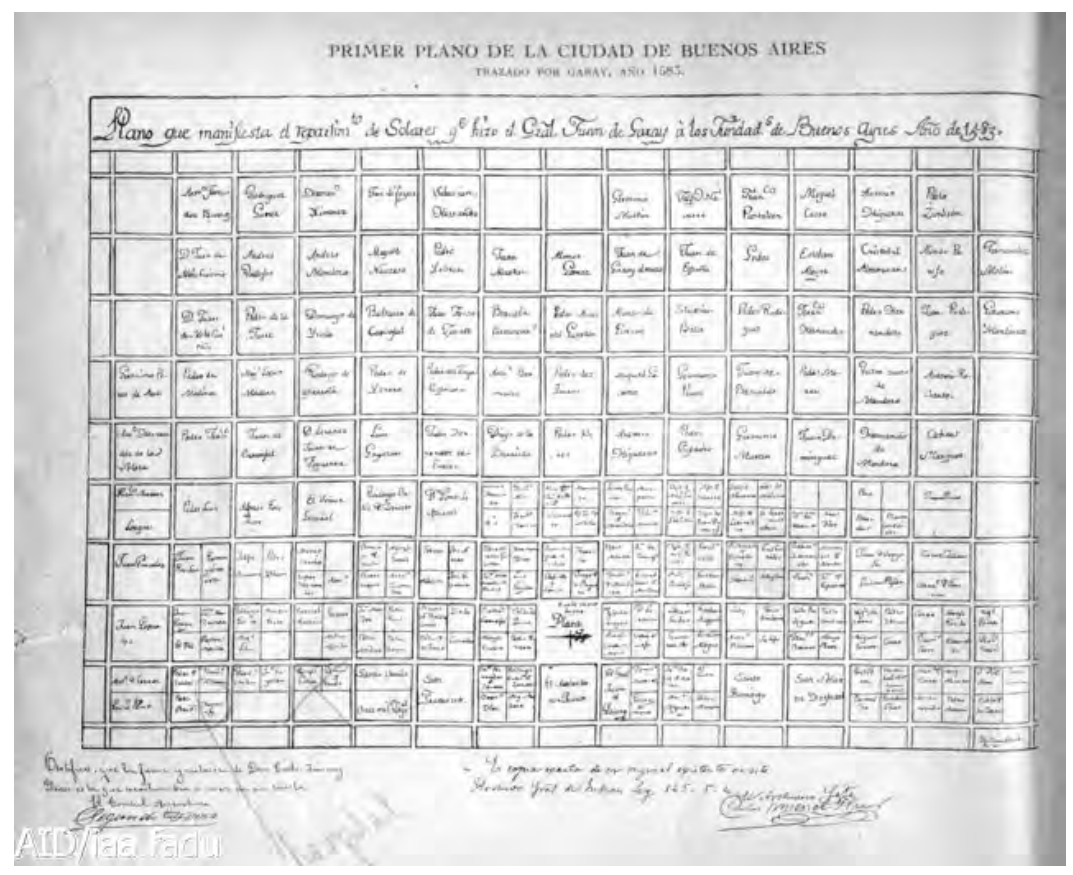

Imagen 1: Primer plano de la Ciudad de Buenos Aires con la repartición de solares que hizo Juan De Garay en 1583. Taullard, A. 1940. Los planos más antiguos de Buenos Aires 1580-1880. Peuser editores. UBA, FADU, IAA, Biblioteca. $N^{0}$ de inventario 4104. AID FADU 


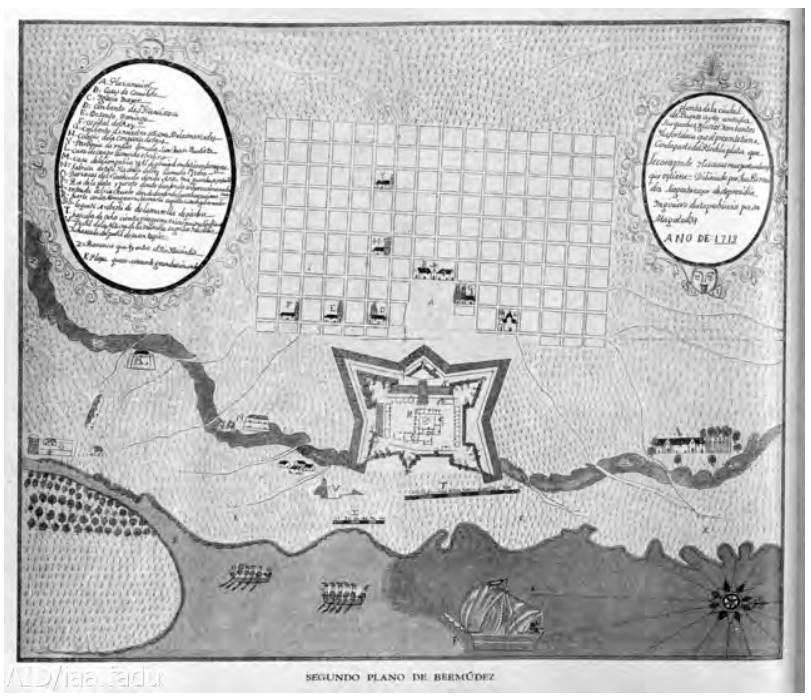

Imagen 2: Planta de la Ciudad de Buenos Aires con todas sus iglesias, conventos y la fortaleza. Taullard, A. 1940. Los planos más antiguos de Buenos Aires 1580-1880. Peuser editores. UBA, FADU, IAA, Biblioteca. $\mathrm{N}^{\circ}$ de inventario 4104. AID FADU

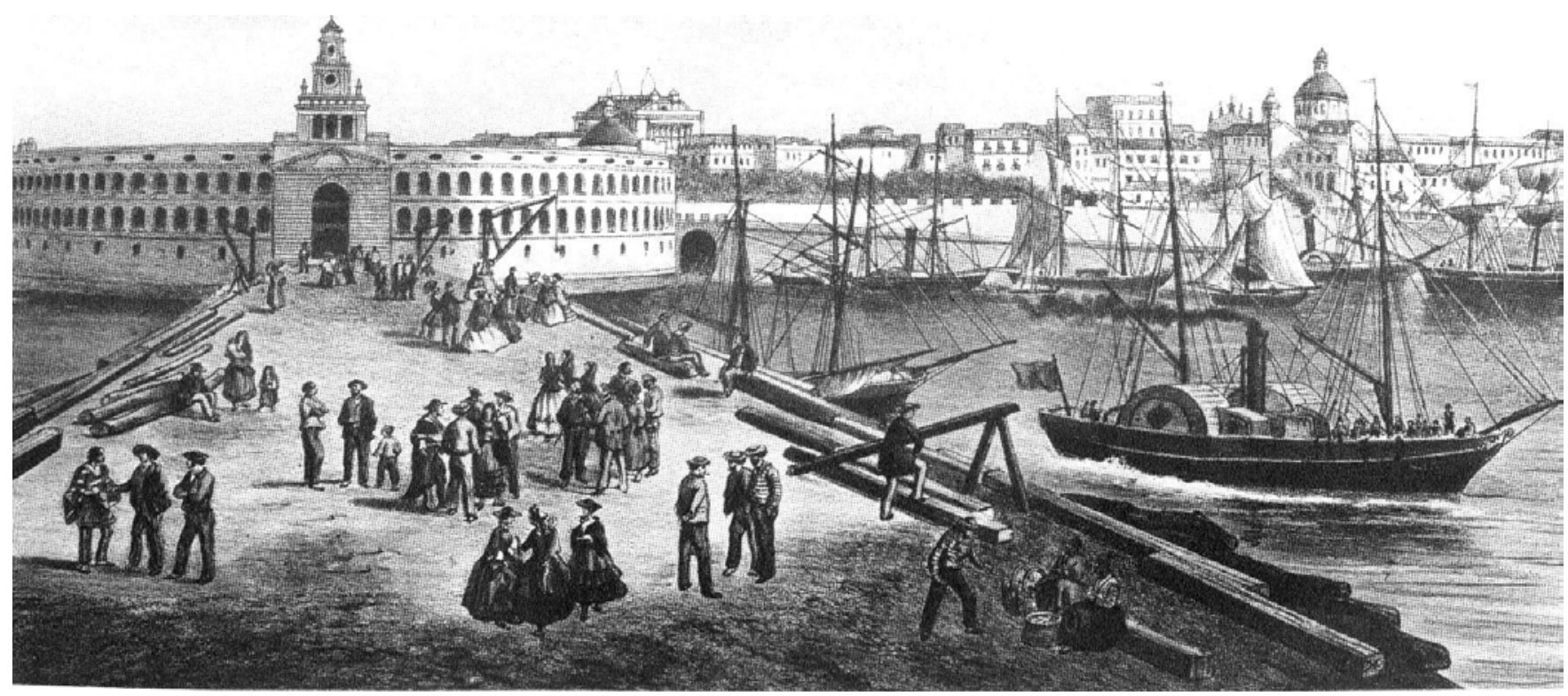

Imagen 3: Representación de la vida portuaria en el Buenos Aires de mediados del siglo XIX. Litografía de Deroy. 1861. 
Teoría y Práctica de la Arqueología Histórica Latinoamericana | Año VIII. Vol. 8 | 2019

ISSN en línea: 2591-2801 | ISSN versión impresa: 2250-866X

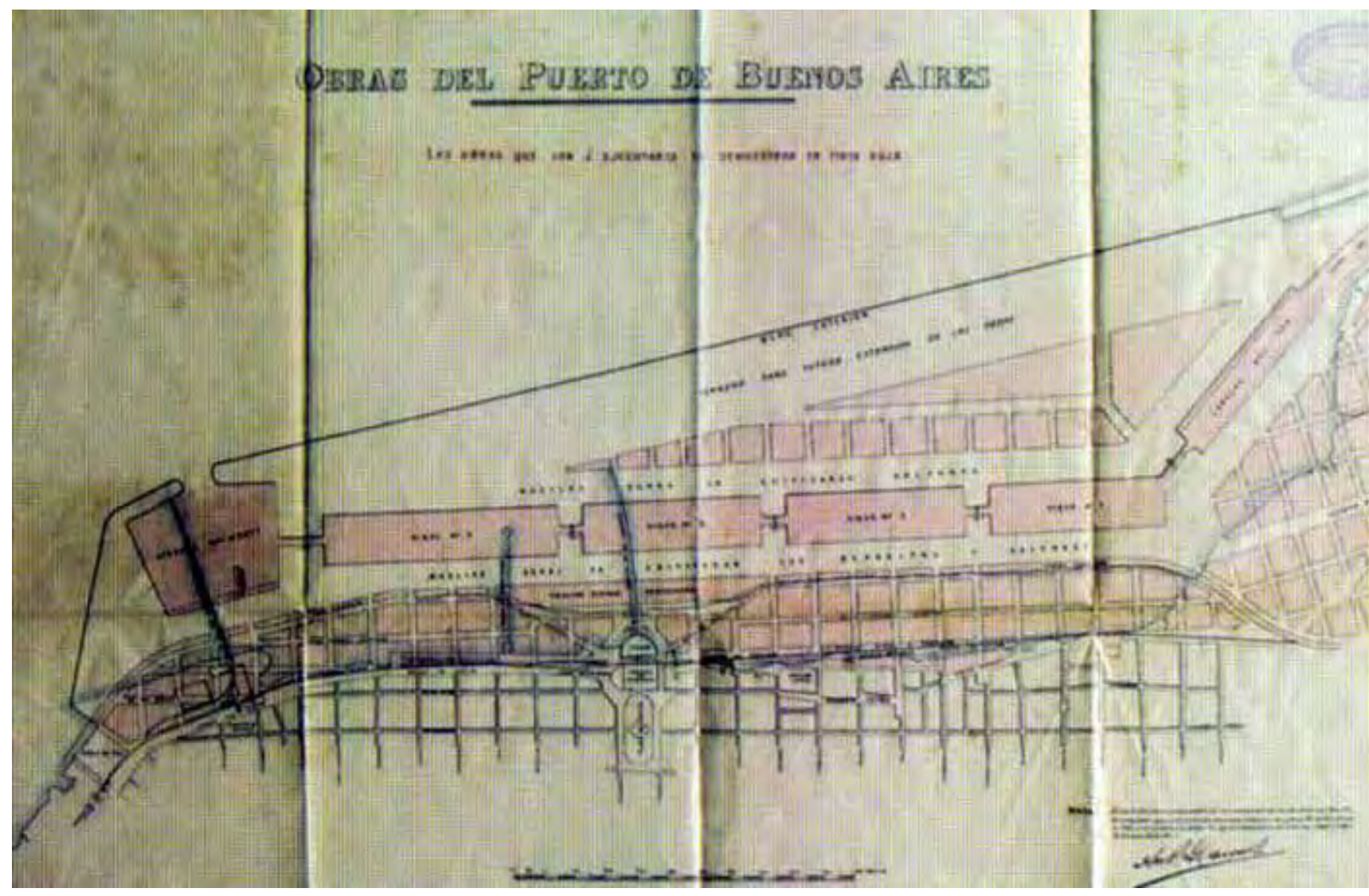

Imagen 4: Plano del proyecto del puerto diseñado por Eduardo Madero. Se desconoce el autor. Circa 1900

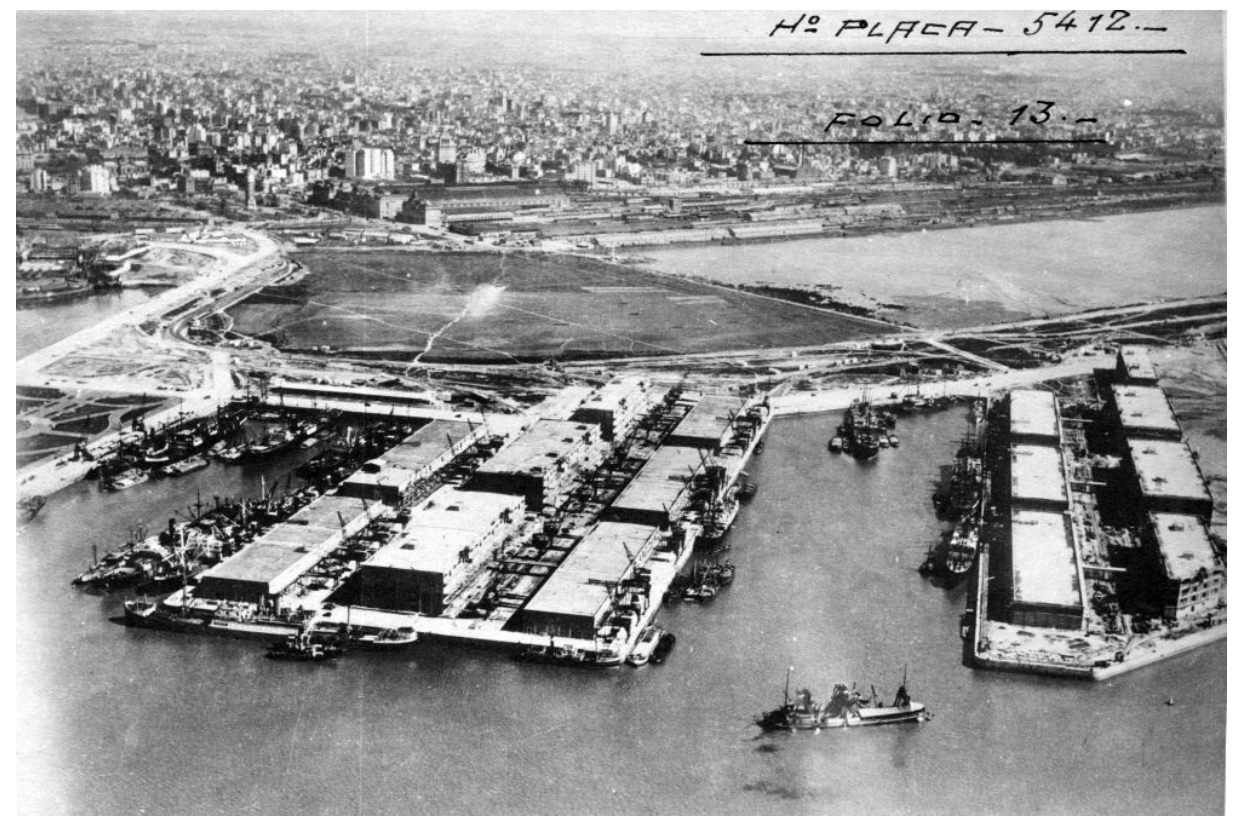

Imagen 5: Vista aérea donde se puede apreciar el Puerto Nuevo con la configuración actual. Se desconoce autor. Circa 1940 
Teoría y Práctica de la Arqueología Histórica Latinoamericana | Año VIII. Vol. 8 | 2019

ISSN en línea: 2591-2801 | ISSN versión impresa: 2250-866X

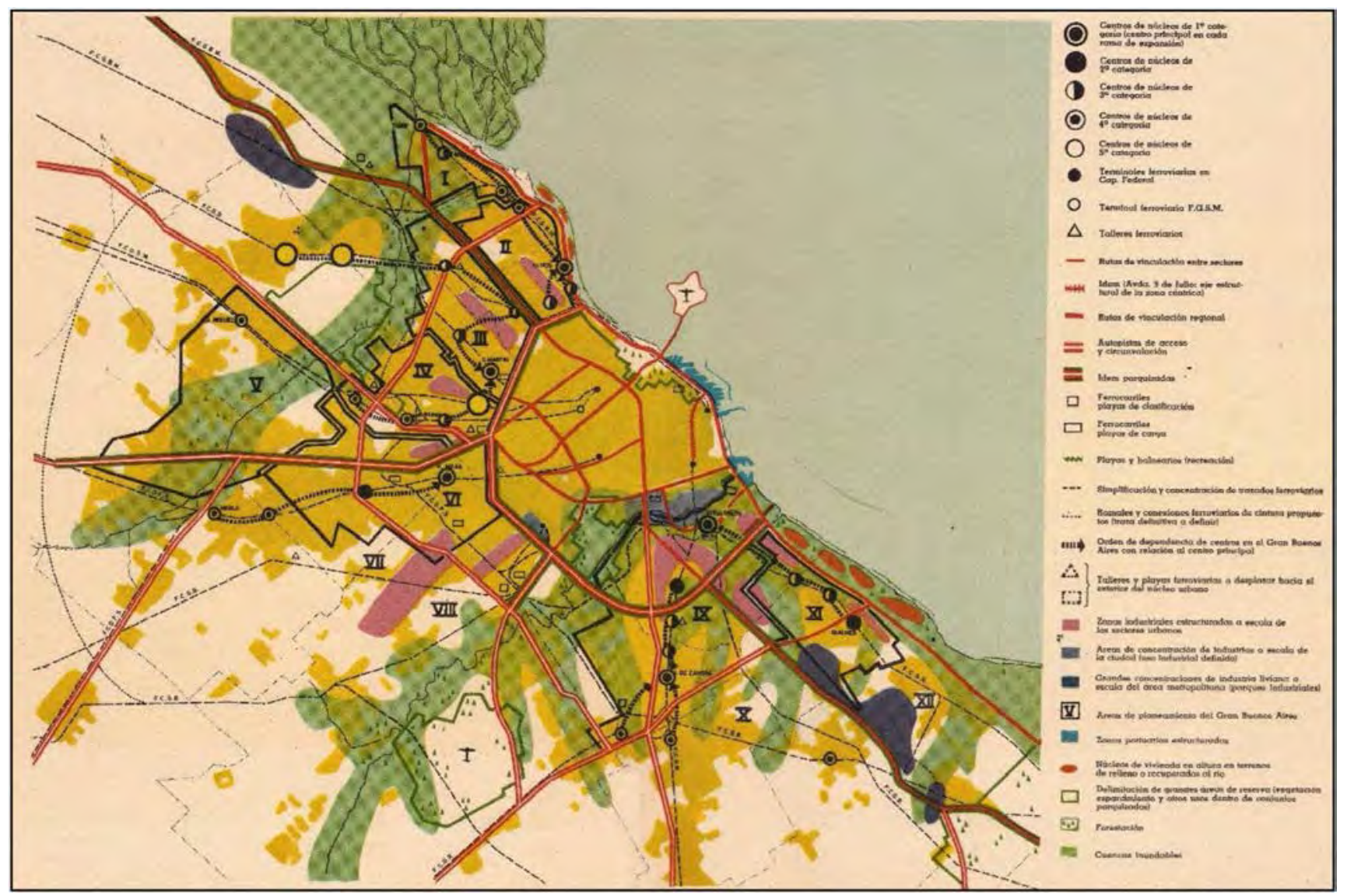

Imagen 6: Plan director de 1958. Propuesta para escala AMBA. Buenos Aires, Municipalidad, Organización del plan Regulador, Informe Preliminar. Etapa 1959-1960, Buenos Aires, 1968.

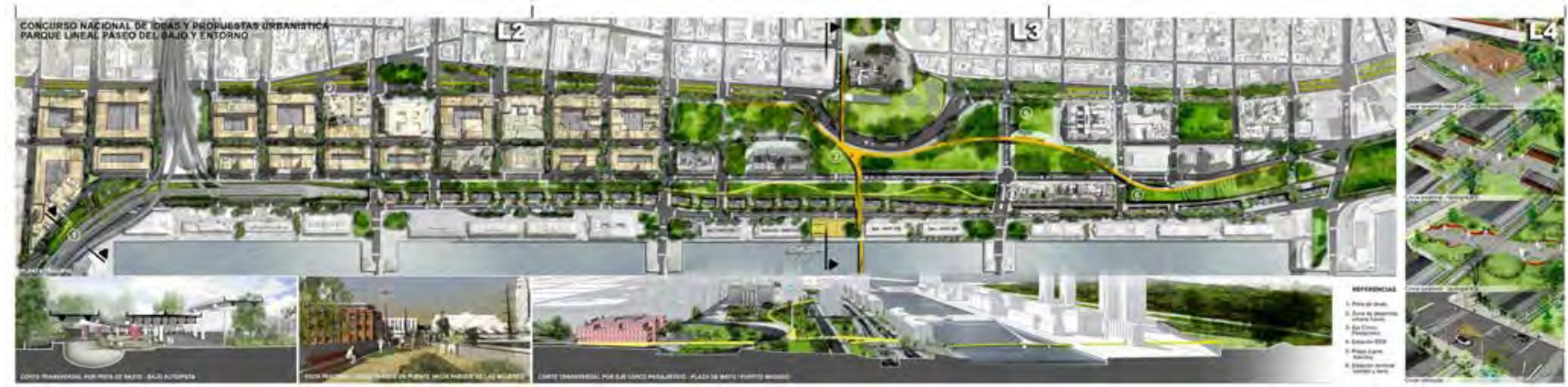

Imagen 7: Anteproyecto del Paseo Del Bajo. 2015. Autor desconocido. Gobierno de la Ciudad de Buenos Aires. Ministerio de Desarrollo Urbano y Transporte. 


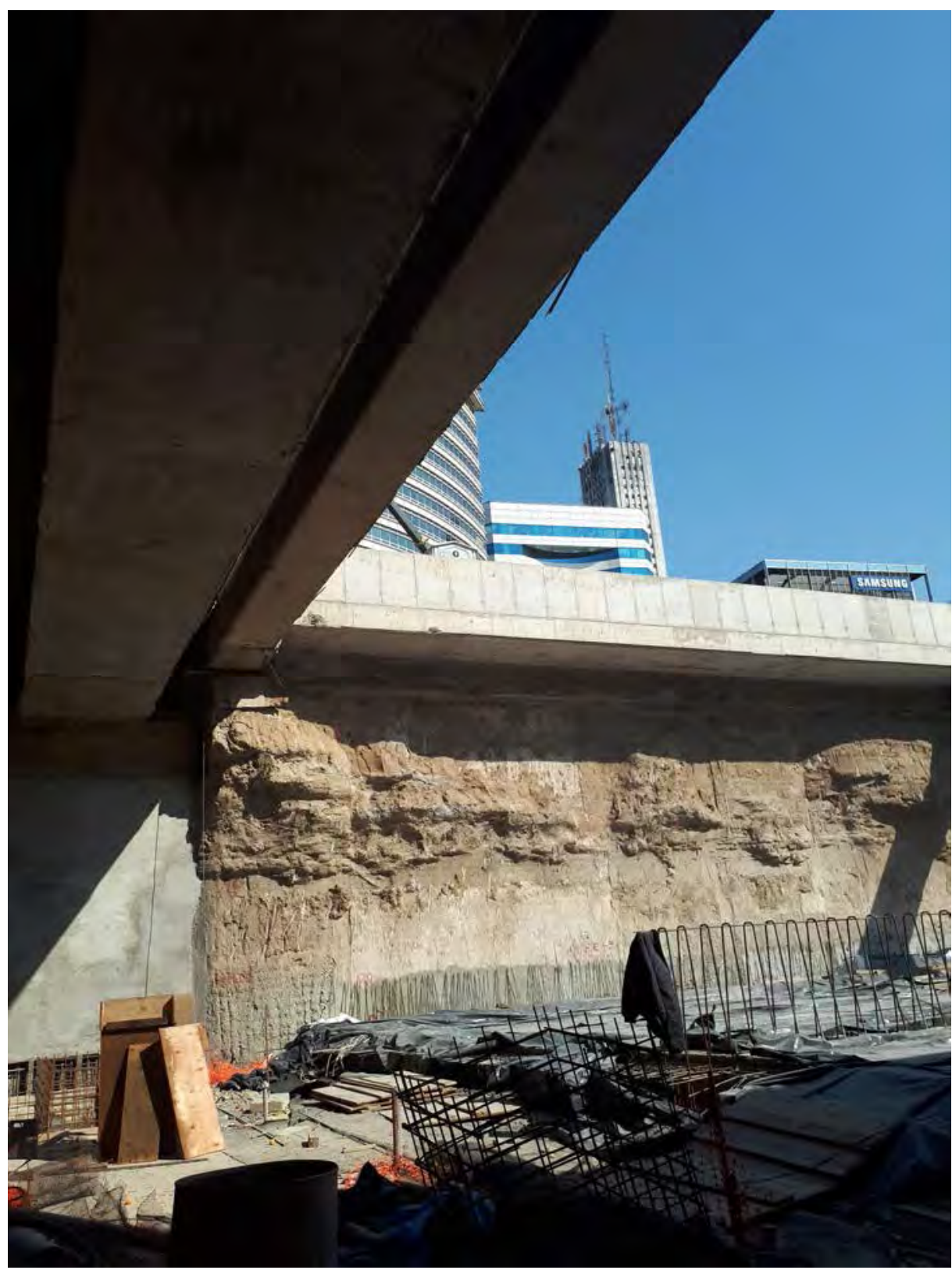

Imagen 8: Vista aérea del “Nudo Retiro”. Arq. Croce, F. 2018. Archivo personal.

\section{Referencias bibliográficas}

ANÓNIMO. Puerto Nuevo. Inicios 1911 a 1925. Buenos Aires, Argentina. Recuperado de http://www. histarmar.com.ar/Puertos/BsAs/PuertoNuevo1-1911.htm

LEZAMA ASTIAGARRAGA, A. (2001). La colonización endógena: una nueva perspectiva sobre el proceso de colonización del Río de la Plata. Fronteras de la Historia. Revista de Historia Colonial Latinoamericana. Bogotá: Instituto Colombiano de Antropología e Historia, volumen 6: 68 - 98. 
Alvarez Kern, A. (Ed.) (2000). Sociedades Iberoamericanas: Reflexiones e Investigaciones Recientes. Porto Alegre, Brasil. EDIPUCRS

Novick, A. (2001). El espejo y la memoria: un siglo de proyectos para la Costanera de Buenos Aires. Berrotarán-Magariños (Moderadores). Seminarios de Crítica. Buenos Aires, Argentina: Instituto de Arte Americano. FADU-UBA.

Schávelzon, D. (2010). Haciendo un mundo moderno: la arquitectura de Edward Taylor (1801-1868). Buenos Aires, Argentina: Olmo ediciones.

Trujillo, Oscar José (2017). Los Habsburgo en el Río de la Plata: Gobernadores de capa y espada en el Buenos Aires colonial temprano, Anuario del Instituto de Historia Argentina, vol. 17, nº 2, 047

Recibido: 10 de junio de 2019

Aceptado: 20 de septiembre de 2019 